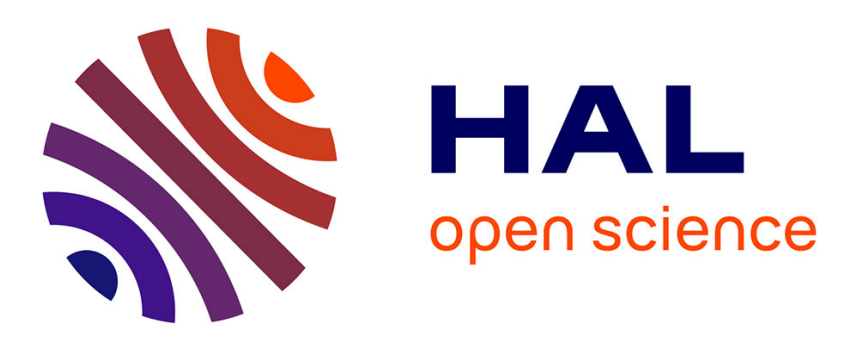

\title{
The impedance response of LaY2Ni9 negative electrode materials after activation
}

\author{
S. Boussami, C. Khaldi, J. Lamloumi, H. Mathlouthi, Hisasi Takenouti, \\ Vincent Vivier
}

\section{To cite this version:}

S. Boussami, C. Khaldi, J. Lamloumi, H. Mathlouthi, Hisasi Takenouti, et al.. The impedance response of LaY2Ni9 negative electrode materials after activation. Journal of Physics and Chemistry of Solids, 2013, 74 (10), pp.1369-1374. 10.1016/j.jpcs.2013.04.013 . hal-00842187

\section{HAL Id: hal-00842187 \\ https://hal.sorbonne-universite.fr/hal-00842187}

Submitted on 12 Feb 2016

HAL is a multi-disciplinary open access archive for the deposit and dissemination of scientific research documents, whether they are published or not. The documents may come from teaching and research institutions in France or abroad, or from public or private research centers.
L'archive ouverte pluridisciplinaire HAL, est destinée au dépôt et à la diffusion de documents scientifiques de niveau recherche, publiés ou non, émanant des établissements d'enseignement et de recherche français ou étrangers, des laboratoires publics ou privés. 


\title{
The impedance response of $\mathrm{LaY}_{2} \mathrm{Ni}_{9}$ negative electrode materials
}

\section{after activation}

\author{
S. Boussami ${ }^{\mathrm{a}^{*}}$, C. Khaldi ${ }^{\mathrm{a}}$, J. Lamloumi ${ }^{\mathrm{a}}$, H. Mathlouthi ${ }^{\mathrm{a}}$, H. Takenouti ${ }^{\mathrm{b}}$, V. Vivier $^{\mathrm{b}}$ \\ ${ }^{\text {a }}$ LMMP, ESSTT, 5 Avenue Taha Hussein, 1008 Tunis, Tunisia. \\ ${ }^{\mathrm{b}}$ UPR 15 CNRS - LISE, UPMC Univ Paris 06, Case 133, 4 place Jussieu, \\ 75252 Paris Cedex 05, France.
}

\section{AbStract}

The electrochemical impedance responses of the $\mathrm{LaY}_{2} \mathrm{Ni}_{9}$ alloy electrode after activation at different states of charge (SOC), immersion time in $7 \mathrm{M} \mathrm{KOH}$ and room temperature was studied. Electrochemical impedance spectrum of the metal hydride electrode obtained was interpreted by an equivalent circuit modelling including the different electrochemical processes taking place on the interface between the $\mathrm{MH}$ electrode and the electrolyte. The results indicate that the electrochemical reaction activity of hydride electrode was markedly enhanced with increasing state of charge. The hydrogen diffuses in the bulk of the alloy and this process is not the limiting step for the hydrogen absorption. During a long immersion time a continuous nanocrystalline corrosion scale appears and the modification of passive film towards more organized structure is concluded.

Keywords: A. Intermetallic compounds; D. Electrochemical properties; D. Diffusion

\footnotetext{
* Corresponding author: Sami.Boussami@esstt.rnu.tn; Tel: + 21671496 066; Fax: + 21671391066
} 


\section{INTRODUCTION}

Hydrogen may constitute the main energy vector in the future. There is multiple ways of storing hydrogen. An alternative to the use of gaseous pressure tanks is to store hydrogen in metal hydrides. The new family of ternary intermetallic compounds $\mathrm{RM}_{2} \mathrm{Ni}_{9}(\mathrm{R}=$ rare earth or $\mathrm{Ca}, \mathrm{M}=\mathrm{Mg}, \mathrm{Ca}$, Ti or $\mathrm{Y}$ ) is studied in this purpose [1-4]. Among the different electrochemical methods used to study metal hydrides, electrochemical impedance spectroscopy (EIS) exhibits some advantages, such as the possibility of analyzing the system at a given state of charge, which is practically not disturbed by the measurement on account of its operation around an equilibrium state and of the small amplitude of the perturbing signal. Also EIS is one of the most employed techniques to study passive layers formation on different metals and alloys [56]. In this work, we are interested in studying the electrochemical behavior of $\mathrm{AB}_{3}$ type alloy, used as a negative electrode in the Ni-MH battery. This appealed to the electrochemical impedance spectroscopy, which allows us to discern the various processes occurring at the electrode | electrolyte surface, such as the charge transfer, the diffusion and others. Many works has studied the spectra with state of discharge [7]. Currently, it is very interesting to study the spectra after activation and at equilibrium potential of the electrode at different states of charge (SOC) and with the immersion time.

\section{EXPERIMENTAL PROCEDURES}

\subsection{Preparation and characterization of the electrodes}

The alloy samples were prepared by induction melting of the pure La, Y, and Ni elements in the atomic ratio of 1:2:9 followed by annealing at $750^{\circ} \mathrm{C}$ for three weeks to ensure good homogeneity. 
The electrodes were prepared by so-called "latex" technology [8]. The composite anodic electrodes were made from the intermetallic active material (grain size $<75 \mu \mathrm{m}$ ) mixed with carbon black and PTFE [9] in the weight ratio of 90:5:5. The mixtures were spread out and compressed in sheets $0.25 \mathrm{~mm}$ thick on $0.7 \times 0.7 \mathrm{~cm}^{2}$ nickel grids which constitute of the current collector. They were impregnated in $7 \mathrm{M} \mathrm{KOH}$ under primary vacuum before any electrochemical test. The samples were observed before and after electrochemical cycling by scanning electron microscopy (SEM).

\subsection{Charge-discharge cycling test}

The electrochemical measurements were performed by using a Gamry Framework constituted of a Potentiostat-Galvanostat at a room temperature in a conventional three electrode cell. The electrolyte consisted of a $7 \mathrm{M} \mathrm{KOH}$ deoxygenated by a continuous flow of argon through the cell. $\mathrm{Ni}$ and an $\mathrm{Hg} / \mathrm{Hg}_{2} \mathrm{SO}_{4}$ electrode were used as a counter and a reference electrode, respectively. The activation of the electrode was realized by galvanostatic charging at $\mathrm{C} / 3$ regime then discharging at $\mathrm{D} / 3$ regime until the potential reaches the cut-ff voltage $\mathrm{E}=-0.6$ $\mathrm{V}$ versus $\mathrm{Hg} / \mathrm{Hg}_{2} \mathrm{SO}_{4}$ for many cycles.

\subsection{Eelectrochemical impedance spectroscopy test (EIS)}

All EIS measurement was started after activation of the alloy when the equilibrium potential was reached. Pt electrode was used as a counter electrode. A frequency range explored was from $100 \mathrm{kHz}$ to $1 \mathrm{mHz}$, and the ac perturbing signal was $10 \mathrm{mV}$ peak-to-peak.

\section{RESULTS AND DISCUSSION}

Fig. $1 \mathrm{~A}-\mathrm{D}$ shows the EIS of the $\mathrm{LaY}_{2} \mathrm{Ni}_{9}$ alloy electrode after activation for different states of charge (SOC) and at room temperature. All of these spectra exhibit a small arc of circle in the high-frequency region and a large loop in the low frequency region, which exhibits 
marked dependence on the SOC. As a SOC increases, the cord of the high frequency loop decreases.

The software ZSimpWin 3.1 was used to develop a circuit model from the spectroscopy data. The modeling process was iterative, using the Chi-square $\left(\chi^{2}\right)$ value for the entire model and the percent error values for each circuit component to determine the fit of a given model to the experimental data. The $\chi^{2}$ value was defined by the following equation:

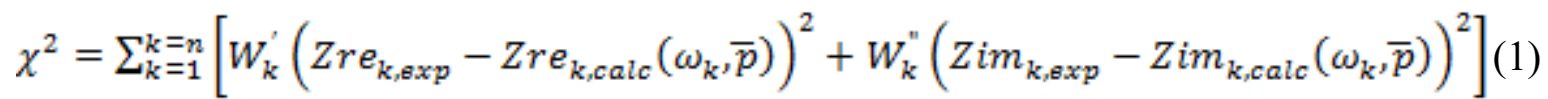

Where $\mathrm{Zre}_{\mathrm{k}, \exp }\left(\mathrm{Zre}_{\mathrm{k}, \mathrm{calc}}\right)$ and $\mathrm{Zim}_{\mathrm{k}, \exp }\left(\mathrm{Zim}_{\mathrm{k}, \mathrm{calc}}\right)$ are the real and imaginary parts of impedance experimental (calculated), respectively, at the frequency $\omega_{\mathrm{k}}, \mathrm{W}{ }_{\mathrm{k}}$ and $\mathrm{W}{ }^{\prime}{ }_{\mathrm{k}}$ are the data statistic weights and $n$ is the number of perturbing a.c. signals used in the fitting calculation. The proposed equivalent circuit used for fitting the EIS of the $\mathrm{LaY}_{2} \mathrm{Ni}_{9}$ alloy electrode, as shown in Fig. 2 [10]. In this circuit, $R_{e}$ was assigned to the electrolyte resistance between the reference and working electrodes. $R_{t c}$ is attributed to the charge-transfer resistance of the hydrogen insertion process. The constant phase element $(\mathrm{Q}=\mathrm{CPE})$, with the associated impedance, $Z_{\mathrm{CPE}}=1 /\left[\mathrm{Y}_{\mathrm{CPE}}(\mathrm{j} \omega)^{\mathrm{n}}\right]$ [11-13], is introduced because the semicircle is depressed. $C_{d l}$ is the capacitance of the double layer, $n_{\mathrm{dl}}$ allowed representing a depressed feature of capacitive loop, $C P E_{a d}$ is modeled as constant-phase element for the frequency depending adsorption capacity of hydrogen on the surface $\left(C_{a d}\right)$ and $R_{a d}$ is the resistance for the hydrogen adsorption on the alloy surface. Constant phase element (CPE) is used in this circuit model to take into account the heterogeneity of the electrode surface for reactivity and roughness. The O element is introduced to simulate the diffusion of hydrogen through in the alloy, with the associated tangent hyperbolic impedance,

$$
Z_{O}=\frac{1}{Y_{O} \sqrt{(j \omega)}} \operatorname{tangh}[B \sqrt{(j \omega)}]
$$


Table 1 summarizes the value of parameters determined by the regression calculation. The resistance of the electrolyte was valued to $R_{e} \approx 0.45 \Omega \mathrm{cm}^{2}$. Fig. 3 shows the variation of the charge-transfer resistance $R_{t c}$ and the exchange current density $I_{0}$ as a function of state of charge. The decrease of the charge-transfer resistance is mainly attributed to the improvement of the surface electrocatalytic activity of the $\mathrm{MH}$ electrode. The exchange current density $\mathrm{I}_{0}$ is estimated by the following formula [14] at the equilibrium potential:

$$
I_{0}=\frac{R T}{n F} \frac{1}{R_{t c}}
$$

Where $\mathrm{R}$ is the gas constant, $\mathrm{n}(=1)$ is the number of the exchanged electrons, $\mathrm{T}$ is the absolute temperature and $\mathrm{F}$ is the faraday constant $\left(96500 \mathrm{C} \mathrm{mol}^{-1}\right)$. It can be seen that the $\mathrm{I}_{0}$ value of the alloy electrode increases with the SOC, this implies that the reactivity of the $\mathrm{MH}$ electrode is improved with increasing state of charge. Using micropolarization technique, Tafel polarization technique and EIS, Popovic et al. [15] found that the exchange current density of the $\mathrm{AB}_{5}$ alloy electrode increases with increasing hydrogen concentration in the alloy electrode and the values of the exchange current determined by AC impedance are in good agreement with values obtained by micropolarization and Tafel polarization. The double layer capacitance values were deduced from the equation [16]:

$$
Y_{d l}=C_{d l}^{n_{d I}}\left(R_{e}^{-1}+1 / R_{t e}\right)^{1-n_{d l}}
$$

The roughness factor, $r_{f}$ defined as the ratio of the $C_{d l}$ values and the usual value for metal electrodes of $20 \mu \mathrm{Fcm}^{-2}$ [17,18]. Fig. 4 shows the variation of the double layer capacitance $C_{d l}$ and the roughness factor $r_{f}$. The value of $C_{d l}$ increases from $0.13 \mathrm{mF} \mathrm{cm}^{-2}$ at $20 \% \mathrm{SOC}$ to $0.25 \mathrm{mF} \mathrm{cm}^{-2}$ at $100 \% \mathrm{SOC}$. The surface roughness estimated is between 6.6 and 12.8. An experimental study of Kerner and Pajkossy [19] showed that capacitance dispersion on solid electrodes was due to surface disorder (i.e. heterogeneities on the atomic scale) rather than 
roughness (i.e. geometric irregularities much larger than those on the atomic scale). Kim et al. [20] also showed that the contribution of surface heterogeneity can be much higher than the contribution of the surface irregularity to the capacitance dispersion.

The diffusion coefficient of hydrogen $D_{H}$ can be calculated from the Warburg's perfactor $\mathrm{A}_{\omega}$ [21].

$$
A_{\omega}=\frac{V_{m}}{F S \sqrt{2 D_{H}}} \frac{d E}{d x}
$$

Where $\mathrm{V}_{\mathrm{m}}$ is the molar volume $\left(324 \mathrm{~cm}^{3} \mathrm{~mol}^{-1}\right), \mathrm{S}$ is the geometric area $\left(1 \mathrm{~cm}^{2}\right)$ and $\mathrm{dE} / \mathrm{dx}$ is the slope of the electrochemical discharge isotherm every at $\mathrm{x}$ value at $25^{\circ} \mathrm{C}$ for $\mathrm{LaY}_{2} \mathrm{Ni}_{9}$ intermetallic compound. The Warburg's perfactor $\mathrm{A}_{\omega}$, can be estimated from the admittance $\mathrm{Y}_{\mathrm{O}}$, deduced from the fitting of impedance spectra [22].

$$
\begin{aligned}
& \frac{A_{\omega}}{\sqrt{\omega}}(1-j)=\frac{1}{Y_{0}(j \omega)^{1 / 2}}=\frac{1}{\sqrt{2 \omega} Y_{0}}(1-j) \\
& A_{\omega}=\frac{1}{\sqrt{2} Y_{0}}
\end{aligned}
$$

Combining (eq. 5) with (eq. 7), we can obtain [23]:

$$
D_{H}=\left[\frac{V_{m} Y_{0}}{F S} \frac{d E}{d x}\right]^{2}
$$

The hydrogen diffusion coefficient $D_{H}$, is $7.2110^{-12}, 2.2810^{-10}$ and $1.810^{-12} \mathrm{~cm}^{2} \mathrm{~s}^{-1}$, respectively for $50 \%, 70 \%$ and $100 \%$ of SOC. A similar value was found by the potential-step method [24,25] and EIS method at 50\% of DOD [26]. The value of the diffusion penetration $\delta$, deducted from the parameter B by the following equation: $\delta=B \sqrt{D_{H}}$, is estimated to be around $\delta \sim 39 \mu \mathrm{m}$ and $4.6 \mu \mathrm{m}$. These values are lower compared with $0.25 \mathrm{~mm}$, thick of the 
sheets. Relying on the scanning electron microscopy observation (Fig. 5) we can deduce that the hydrogen diffuses in the bulk of the alloy and this process is not the limiting step for the hydrogen absorption.

The adsorption capacitance of hydrogen on the surface $C_{a d}$, deduced from the equation $C_{a d}=\left(Y_{a d} R_{a d}\right)^{1 / n_{a d}} / R_{a d}$, and the resistance for the hydrogen adsorption $R_{a d}$ are shown in Fig. 6. It can be seen that the $R_{a d}$ values remains essentially constant between $0 \%$ and $70 \%$ of SOC thereafter decrease sharply up to $100 \%$ of SOC. The variation in the values of the $C_{a d}$ could be attributed to surface heterogeneity, due to the variations in the microstructure of the alloy when transforming from solid solution phase ( $\alpha$ phase).

Fig. 7A-B shows the impedance diagrams of a $\mathrm{LaY}_{2} \mathrm{Ni}_{9}$ electrode immersed in $7 \mathrm{M} \mathrm{KOH}$ at open circuit condition, during 3 and 4 days in quiescent solution with $100 \%$ SOC. The impedance spectra's are formed by two capacitive loops at the high frequency range and the low frequency range. This last shows an asymmetrical form. This can be attributed to a diffusion impedance process with a finite thickness of diffusion layer. An equivalent electric circuit illustrated in Fig. 8 with three time constants has been tried to reproduce these results. In this circuit, each element is attributed, in agreement with the values obtained of the parameter regression calculation. $R_{e}$ is the electrolyte resistance, $R_{t}$ the charge transfer resistance, $R_{F}$ the faradaic resistance associated likely to the oxidation-reduction process in the passive layer, $C_{d}$ is the double layer capacitance, $C_{F}$ is the faradaic capacitance, $\alpha_{d}$ and $\alpha_{F}$ are the coefficients allowing representing the depressed shape in the Nyquist diagram and $Z_{\text {diff }}$ is the diffusion impedance [27]:

$$
Z_{\text {diff }}=R_{D} \frac{\tanh \sqrt{j \omega \pi_{D}}}{\sqrt{j \omega \pi_{D}}}
$$


With

$$
\tau_{D}=\frac{\delta_{D}^{n}}{D_{H}}
$$

Where $R_{D}$ is the diffusion resistance, $\tau_{D}$ the diffusion time constant and $\delta_{D}$ the thikness of the diffusion layer. Based on the equivalence between (eq. 2) and (eq. 9), $R_{D}$ and $\tau_{D}$ are determinate by: $R_{D}=\mathrm{B} / Y_{O}$ and $\tau_{D}=B^{2}$.

The impedance spectra are then analysed with the software ZSimpWin 3.1. The calculation results are presented in Table 2.

In all cases, the high frequency limit of the measured impedances is close to $0.5 \Omega \mathrm{cm}^{2}$. This resistance corresponds well to that due to the finite conductivity of the medium, that is, the electrolyte resistance. The values of $\alpha_{d}$ and $\alpha_{F}$ are located between 0.8 and 0.9 , the values frequently reported on a solid electrode, and reveal heterogeneity of the electrode surface. The $C_{d}$ values are between 170 and $200 \mu \mathrm{Fcm}^{2}$, these values suggest that the reason of this capacitance could reasonably be attributed to the double layer with the passive film. It can be noticed that the capacitance decreases from 3 to 4 days, which corresponds to the modification of passive film towards more organized structure. The faradic resistance $R_{F}$ increases with the immersion time. As this resistance is to be associated with the stability of the passive film, it can be concluded that the passive film is more stable. The value of $C_{F}$ is compatible with the hypothesis on the origin of this loop attributed to an oxidation-reduction process involving corrosion products. F. Maurel et al. [28,29] have shown that during exposure of alloy to a $\mathrm{KOH}$ aqueous electrolyte, a continuous nanocrystalline corrosion scale and well-defined (hollow or solid) as corrosion products. F. Maurel et al. [30] also studied the effect of yttrium on the corrosion for nickel-metal hydride batteries. The $R_{d}$ increases for 4 days of immersion; however, $\tau_{D}$ is slightly affected. 


\section{Conclusion}

The effect on the $\mathrm{SOC}$ of $\mathrm{AB}_{3}$ alloys, as well as the long time immersion in $\mathrm{KOH}$ in quiescent solution with $100 \%$ SOC, has been studied by EIS. EIS measurements indicate that the kinetic properties of the alloy improved with increasing state of charge, mainly due to a fast hydrogen transfer in the bulk of the alloy and the higher electrocatalytic activity of the surface. The transformation of $\alpha$ to $\beta$ phase is probably a limiting step in the mechanisms of hydrogenation of metal hydride electrode. The value of the exchange current density $I_{0}$ increases with the SOC, indicating a good kinetics of the reaction of hydriding/dehydriding in the $\mathrm{LaY}_{2} \mathrm{Ni}_{9}$ alloy. The penetration depth of hydrogen by diffusion process is estimated to be around $39 \mu \mathrm{m}$ and 4.6 $\mu \mathrm{m}$. The hydrogen diffusion towards the alloy matrix is not the limiting factor for the hydrogen absorption. During a long time immersion in $\mathrm{KOH}$ a corrosion layer appears and the modification of passive film towards more organized structure.

\section{Acknowledgements}

The authors would like to express their gratefulness towards Mr. Latroche (LCMTR, CNRS, France, CMCU PHC Utique: 10G1208) for having given them the opportunity to prepare the alloys in their laboratory. 


\section{REFERENCES}

[1] J. Zhang, F. Fang, S. Zheng, J. Zhu, G. Chen, D. Sun, M. Latroche, A. PercheronGuégan, Journal of Power Sources 172 (2007) 446-450.

[2] B. Liao, Y.Q. Lei, G.L. Lu, L.X. Chen, H.G. Pan, Q.D. Wang, J. Alloys Compd. 356-357 (2003) 746-749.

[3] K. Kadir, T. Sakai, I. Uehara, J. Alloys Compd. 302 (2000) 112-117.

[4] A.V. Soloninin, A.L. Buzlukov, A.V. Skripov, M. Latroche, V.P. Boncour, Journal of Solid State Chemistry 182 (2009) 586-591.

[5] D.D. Macdonald, A. Sun, Electrochim. Acta 51 (2006) 1767-1779.

[6] S. Joiret, M. Keddam, X.R. Novoa, M.C. Pérez, C. Rangel, H. Takenouti, Cement \& Concrete Composites 24 (2002) 7-15.

[7] Elida B. Castro, Silvia G. Real, Alejandro Bonesi, Arnaldo Visintin, Walter E. Triaca, Electrochim. Acta 49 (2004) 3879-3890.

[8] H. Mathlouthi, J. Lamloumi, M. Latroche, A. Percheron-Guégan, Ann. Chim. Sci. Mat., 22 (1997) 241-244.

[9] M. Geng, J. Han, F. Feng and D.O. Northwood, J. Electrochem. Soc. 146 (1999) 23712375 .

[10] O.E. Barcia, E. D’Elia a, I. Frateur, O.R. Mattos, N. Pébère, B. Tribollet, Electrochim. Acta 47 (2002) 2109-2116.

[11] J.-B. Jorcin, M.E. Orazem, N. Pébère, B. Tribollet, Electrochim. Acta 51 (2006) 14731479.

[12] M. Sanchez, J. Gregori, C. Alonso, J.J. Garcia-Jareno, H. Takenouti, F. Vicente, Electrochim. Acta 52 (2007) 7634-7641. 
[13] B.A. Boukamp, Solid State Ionics 169 (2004) 65-73.

[14] N. Kuriyama, T. Sakai, H. Miyamura, I. Uehara, H. Ishikawa, J. Alloys Compd. 202 (1993) 183-197.

[15] M.M. Popović, B.N. Grgur, M.V. Vojnović, P. Rakin, N.V. Krstajić, J. Alloys Compd. $298(2000)$ 107-113.

[16] B. Losiewicz, A. Budniok, E. Rówinski, E. Lagiewka, A. Lasia, Int. J. Hydrogen Energy 29 ( 2004) 145-157.

[17] A.J. Bard, L.R. Faulkner, Electrochimie: Principes, Méthodes et Applications, Maison, Paris, 1983.

[18] S. Trasatti, O.A. Petrii, Pure Appl. Chem. 63 (1991) 711-734.

[19] Z. Kerner, T. Pajkossy, J. Electroanal. Chem. 448 (1998) 139-142.

[20] C.-H. Kim, S.-I. Pyun, J.H. Kim, Electrochim. Acta 48 (2003) 3455-3463.

[21] R. Baddour-Hadjean, H. Mathlouthi, J.P. Pereira-Ramos, J. Lamloumi, M. Latroche, A. Percheron-Guégan, J. Alloys Compd. 356-357 (2003) 750-754.

[22] P. Xu, X.J. Han, B. Zhang, Z.S. Lv, X.R. Liu, J. Alloys Compd. 436 (2007) 369-374.

[23] C. Khaldi, H. Mathlouthi, J. Lamloumi, J. Alloys Compd. 469 (2009) 464-471.

[24] Wanqiang Liu, Xinlu Wang, Wen Hu, Yoshiteru Kawabe, Masaharu Watada, Limin Wang, Int. J. Hydrogen Energy 36 (2011) 616-620.

[25] Zhenwei Dong, Yaoming Wu, Liqun Ma, Lidong Wang, Xiaodong Shen, Limin Wang, Int. J. Hydrogen Energy 36 (2011) 3050-3055.

[26] Hai-Liang Chu, Shu-Jun Qiu, Li-Xian Sun, Yao Zhang, Fen Xu, Min Zhu, Wang-Yu Hu, Int. J. Hydrogen Energy 33 (2008) 755-761. 
[27] P. Drossbach, J. Schulz, Electrochim. Acta 9 (2) (1964) 1391-1404.

[28] F. Maurel, B. Knosp, M. Backhaus-Ricoult, J. Electrochem. Soc. 147 (2000) 78-86.

[29] F. Maurel, M.J. Hytch, B. Knosp, M. Backhaus-Ricoult, Eur. Phys. J. AP 9 (2000) 205213.

[30] F. Maurel, P. Leblanc, B. Knosp, M. Backhaus-Ricoult, J. Alloys Compd. 309 (2000) 8894. 
Table 1: The fitting parameters of the equivalent circuit Fig. 2 for EIS spectra of the $\mathrm{LaY}_{2} \mathrm{Ni}_{9}$ electrode, after activation and at different SOC.

\begin{tabular}{|c|c|c|c|c|c|c|c|c|}
\hline \multirow[t]{2}{*}{$\mathrm{SOC}(\%)$} & \multirow[t]{2}{*}{$R_{e}, \Omega \mathrm{cm}^{2}$} & \multicolumn{4}{|l|}{$C P E_{d l}$} & \multirow[t]{2}{*}{$R_{t c}, \Omega \mathrm{cm}^{2}$} & \multirow[t]{2}{*}{$I_{0}, \mathrm{~mA} \mathrm{~g}^{-1}$} & \multirow[t]{2}{*}{$\chi^{2} \times 10^{-3}$} \\
\hline & & \multicolumn{2}{|c|}{$Y_{d l}, \mathrm{mF} \mathrm{s}^{\mathrm{n}-1} \mathrm{~cm}^{-2}$} & \multicolumn{2}{|c|}{$n_{d l}$} & & & \\
\hline 20 & 0.402 & 0.48 & \multicolumn{3}{|c|}{0.87} & 68.63 & 07.65 & 5.96 \\
\hline 50 & 0.434 & 0.90 & \multicolumn{3}{|c|}{0.84} & 53.22 & 09.90 & 5.95 \\
\hline 70 & 0.443 & 1.00 & \multicolumn{3}{|c|}{0.84} & 27.87 & 18.90 & 4.76 \\
\hline 100 & 0.461 & 1.03 & \multicolumn{3}{|c|}{0.85} & 18.91 & 27.80 & 4.28 \\
\hline \multirow[t]{2}{*}{$\operatorname{SOC}(\%)$} & $C P E_{a d}$ & & \multirow{2}{*}{\multicolumn{2}{|c|}{$R_{a d}, \Omega \mathrm{cm}^{2}$}} & \multicolumn{3}{|l|}{$O$} & $\chi^{2} \times 10^{-3}$ \\
\hline & $Y_{a d}, \mathrm{~F} \mathrm{~s}^{\mathrm{n}-1} \mathrm{~cm}^{-2}$ & $n_{a d}$ & & & \multicolumn{2}{|c|}{$Y_{O}, \mathrm{~F} \mathrm{~s}^{\mathrm{n}-1} \mathrm{~cm}^{-2}$} & $B, \mathrm{~s}^{0.5}$ & \\
\hline 20 & 0.09 & 0.95 & \multicolumn{2}{|c|}{4892.0} & \multicolumn{2}{|l|}{-} & 11.75 & 5.96 \\
\hline 50 & 0.11 & 0.96 & \multicolumn{2}{|c|}{0307.3} & \multicolumn{2}{|c|}{0.08} & 14.69 & 5.95 \\
\hline 70 & 0.10 & 0.91 & \multicolumn{2}{|c|}{0122.7} & \multicolumn{2}{|c|}{0.45} & 14.00 & 4.76 \\
\hline 100 & 0.06 & 0.79 & \multicolumn{2}{|c|}{0001.9} & \multicolumn{2}{|c|}{0.04} & 03.43 & 4.28 \\
\hline
\end{tabular}

Table 2: The fitting parameters of the equivalent circuit Fig. 8 for EIS spectra of the $\mathrm{LaY}_{2} \mathrm{Ni}_{9}$ electrode, after activation at $100 \%$ SOC.

\begin{tabular}{lllllllll}
\hline Days & $R_{e}\left(\Omega \mathrm{cm}^{2}\right)$ & $R_{t}\left(\Omega \mathrm{cm}^{2}\right)$ & $\left.C_{d}(\mu \mathrm{Fcm})^{-2}\right)$ & $R_{F}\left(\mathrm{k} \Omega \mathrm{cm}^{2}\right)$ & $C_{F}\left(\mathrm{Fcm}^{-2}\right)$ & $R_{d}\left(\Omega \mathrm{cm}^{2}\right)$ & $T_{d}(\mathrm{~s})$ & $\chi^{2} \times 10^{-4}$ \\
\hline 3 & 0.521 & 3.881 & 200 & 0.4 & 0.15 & 26 & 0.025 & 1.93 \\
4 & 0.516 & 4.747 & 170 & 1.75 & 0.15 & 30 & 0.022 & 2.15
\end{tabular}




\section{FigURE CAPTIONS}

Figure 1: Electrochemical impedance spectra at different SOC and at open circuit condition (A) $20 \% \mathrm{SOC}$, (B) $50 \% \mathrm{SOC},(\mathrm{C}) 70 \% \mathrm{SOC}$, (D) $100 \% \mathrm{SOC}$.

Figure 2: The electrical equivalent circuit model to represent experimental impedance spectra of $\mathrm{Lay}_{2} \mathrm{Ni}_{9}$ electrode with SOC.

Figure 3: Charge-transfer resistance and the exchange current density of the $\mathrm{LaY}_{2} \mathrm{Ni}_{9}$ alloy as a function of the state of charge.

Figure 4: Double layer capacitance and roughness factor of the $\mathrm{Lay}_{2} \mathrm{Ni}_{9}$ alloy as a function of the state of charge.

Figure 5: SEM picture of the $\mathrm{LaY}_{2} \mathrm{Ni}_{9}$ alloy (a-b) before, (c-d) after cycling in $\mathrm{KOH}$.

Figure 6: Adsorption capacitance of hydrogen on the surface and resistance for the hydrogen adsorption as a function of the state of charge.

Figure 7: The impedance diagrams of a $\mathrm{LaY}_{2} \mathrm{Ni}_{9}$ electrode immersed in $7 \mathrm{M} \mathrm{KOH}$ at $100 \%$ SOC.

Figure 8: The electrical equivalent circuit model to represent experimental impedance spectra of $\mathrm{LaY}_{2} \mathrm{Ni}_{9}$ electrode with immersion time. 
(A)

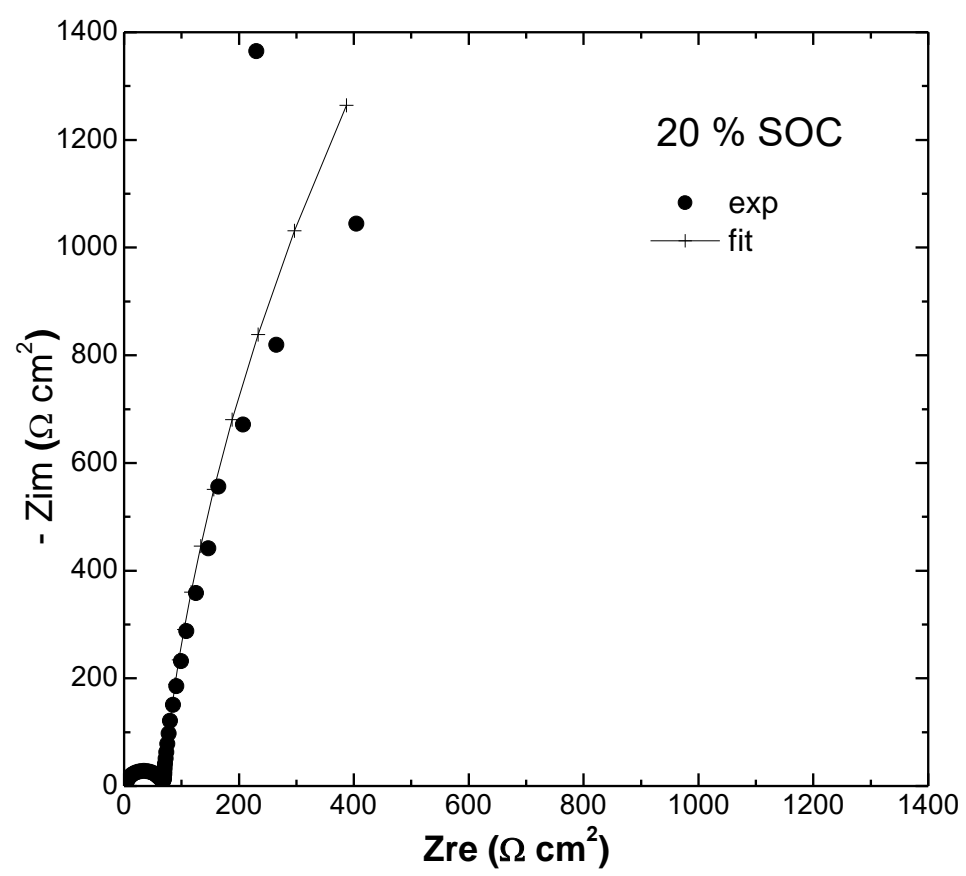

(B)

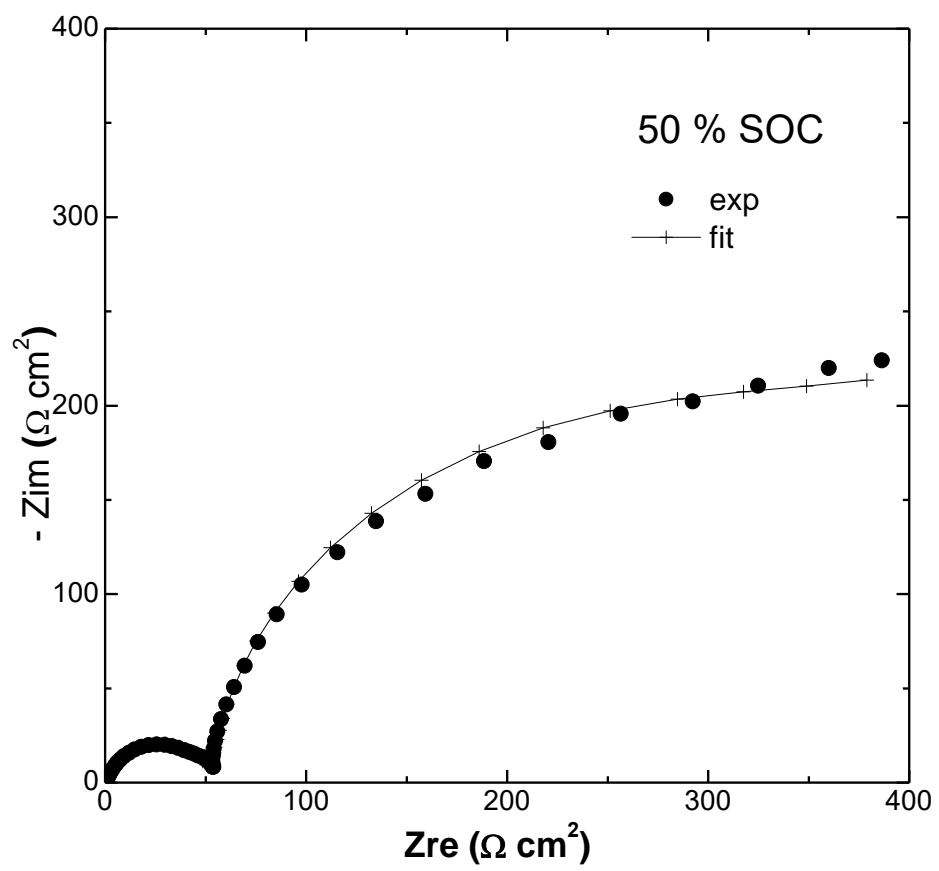


(C)

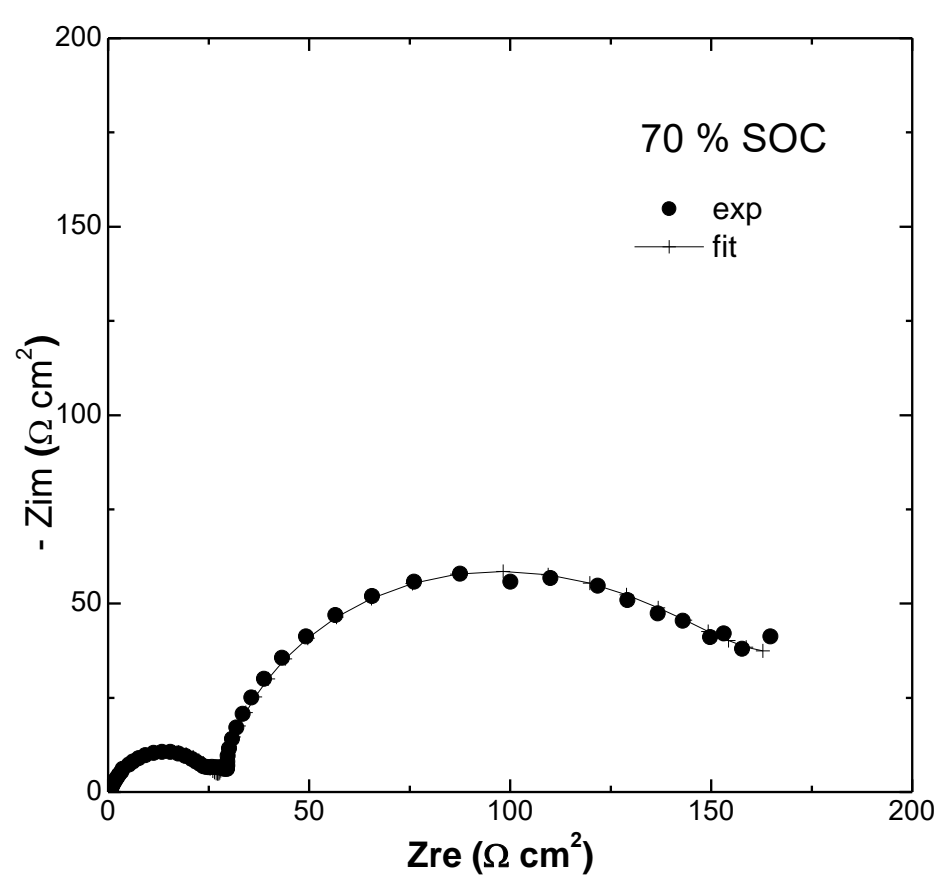

(D)

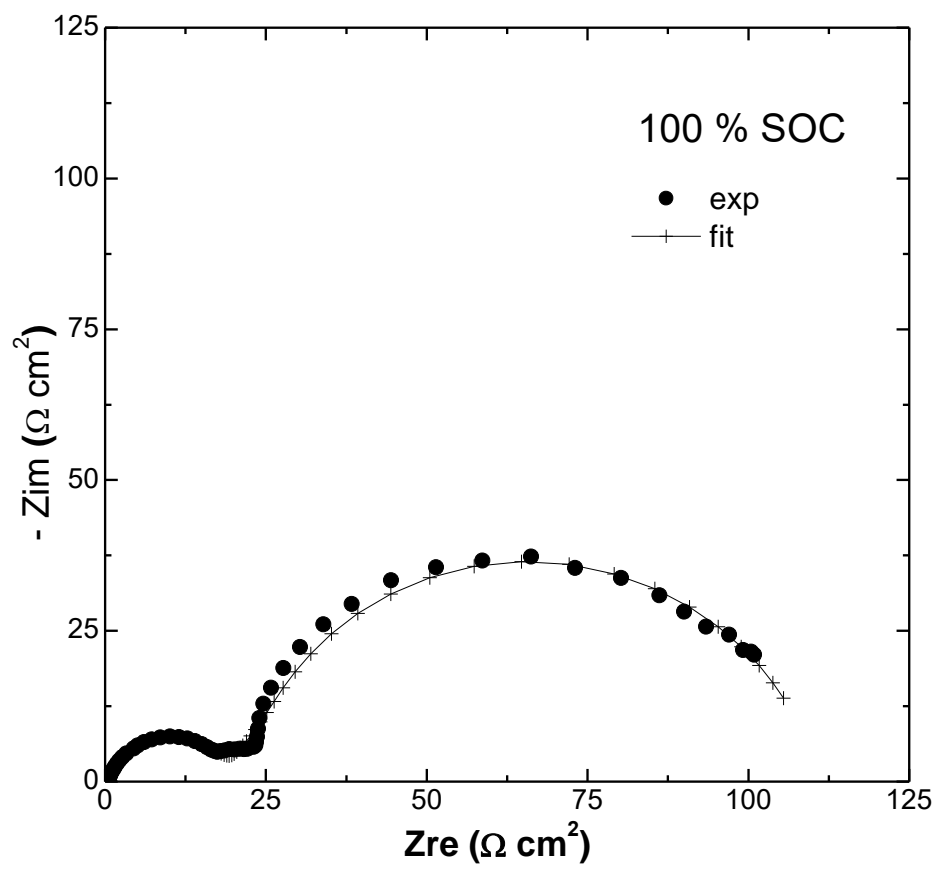

Figure 1 


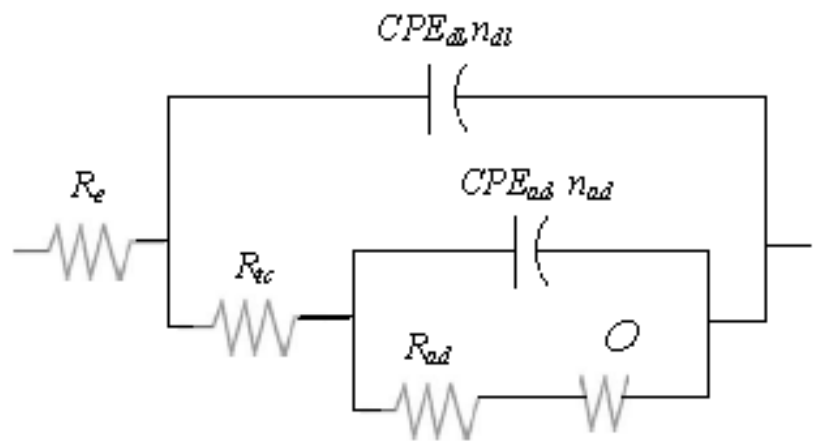

Figure 2

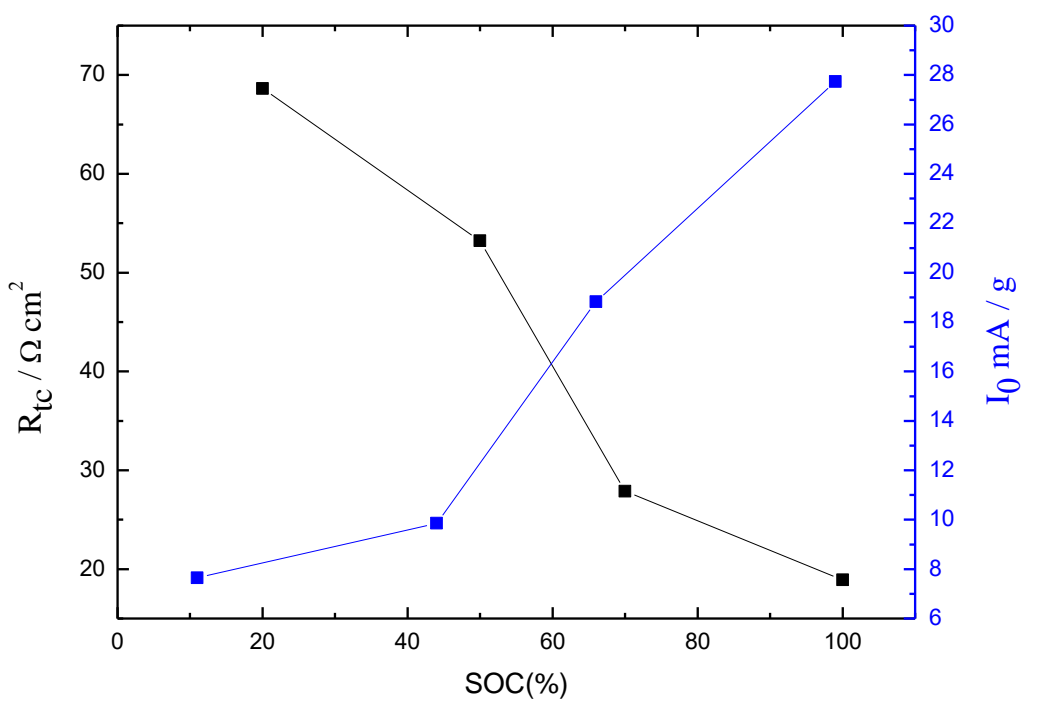

Figure 3 


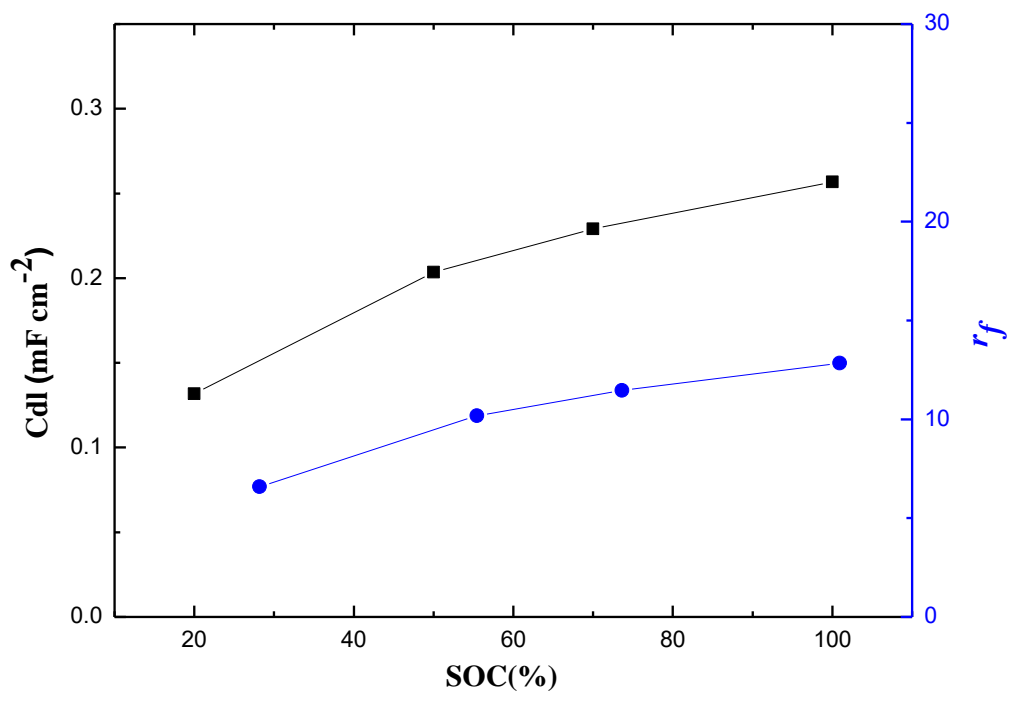

Figure 4 
(A)

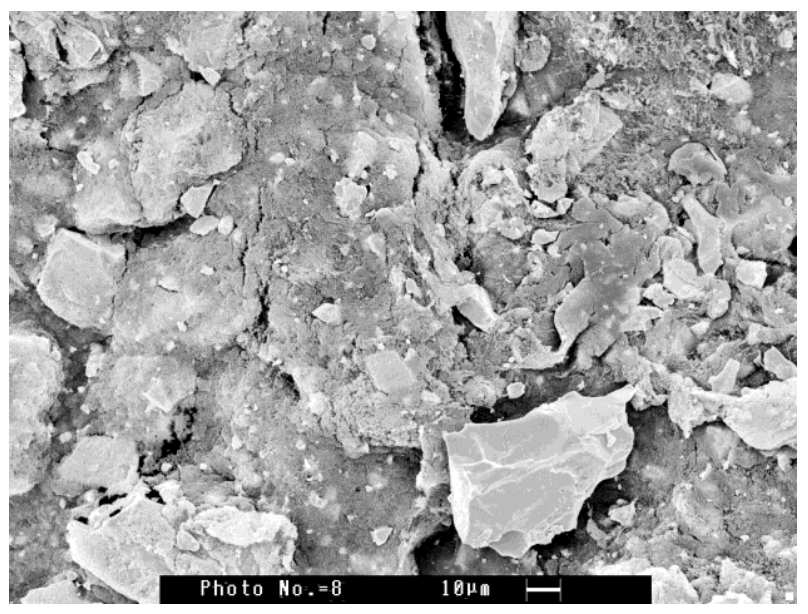

(B)

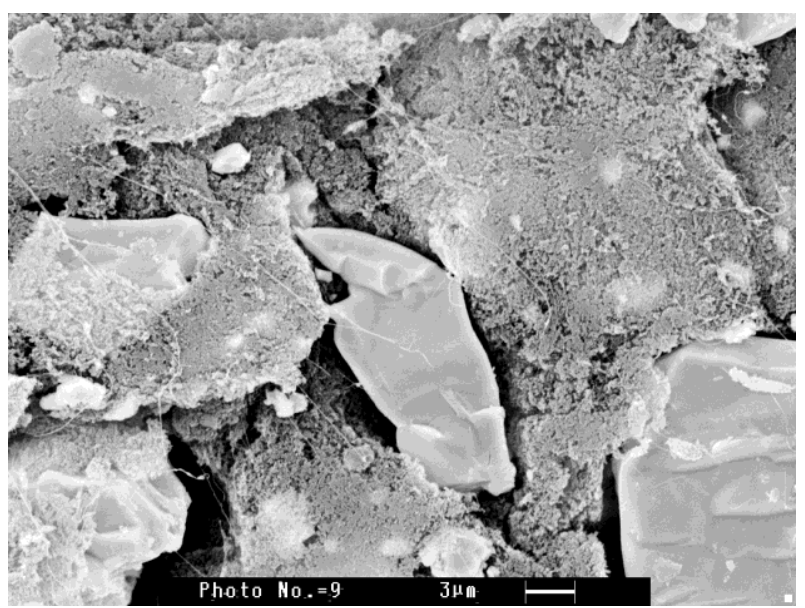


(C)

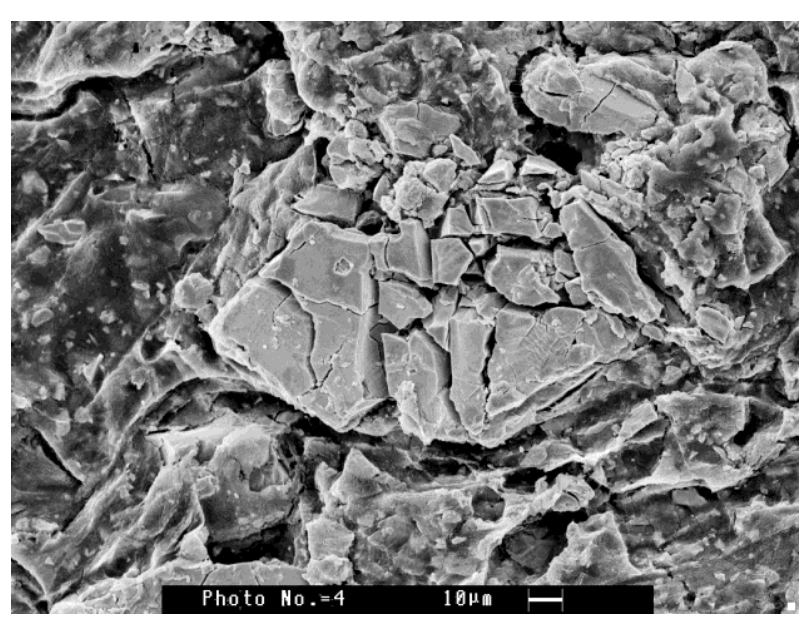

(D)

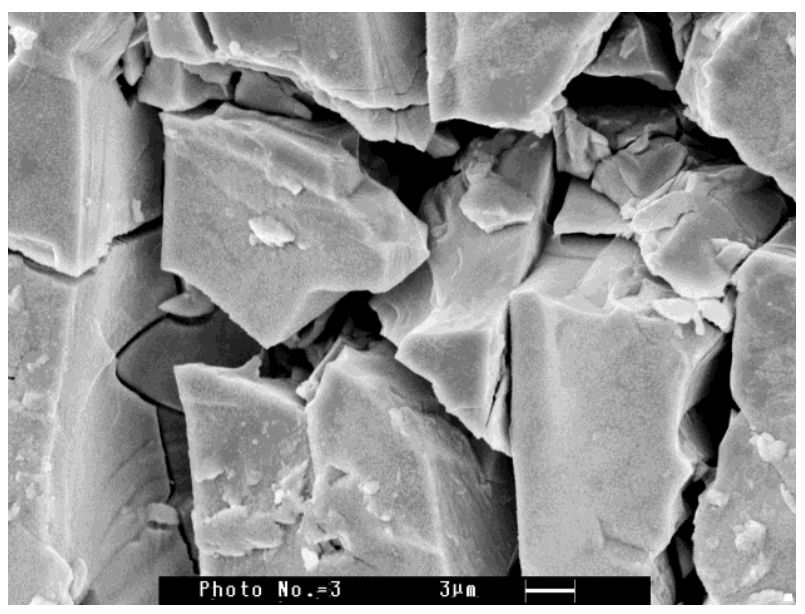

Figure 5 


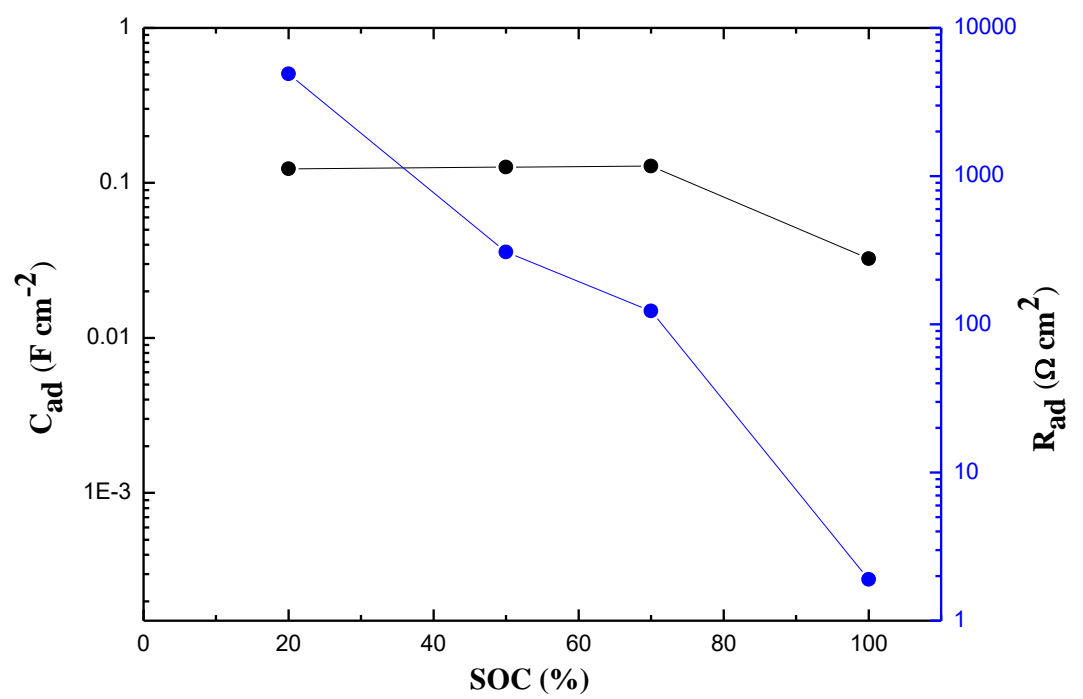

Figure 6 
(A)

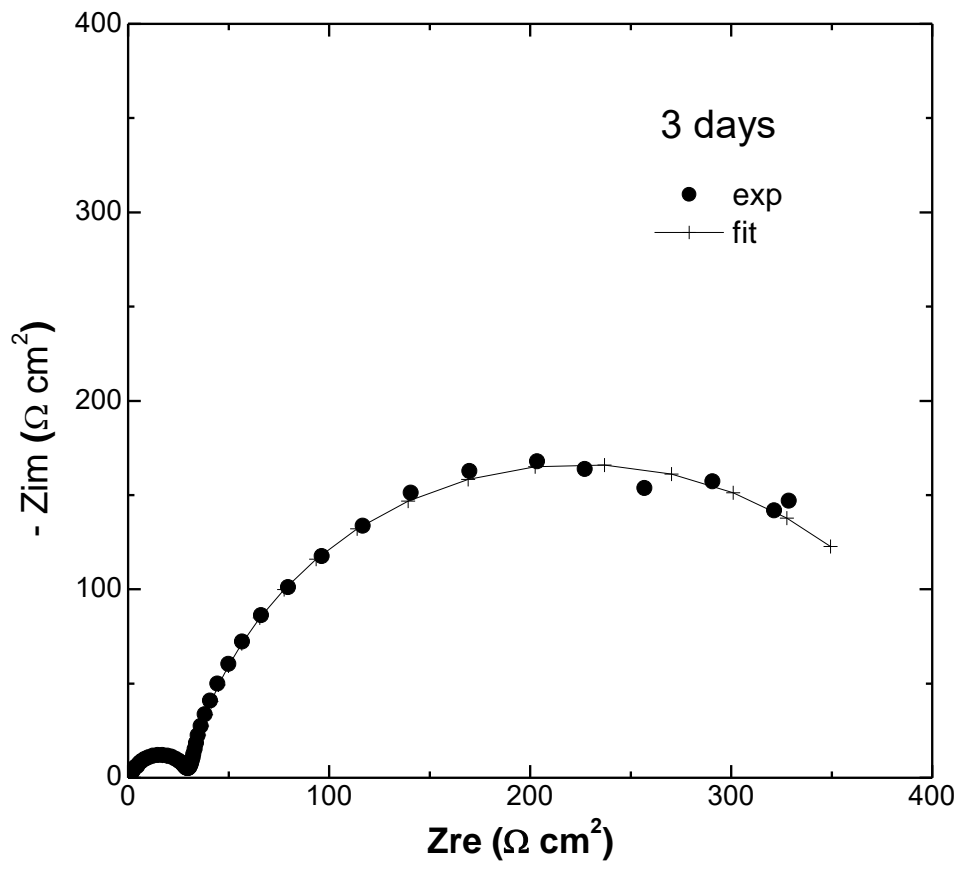

(B)

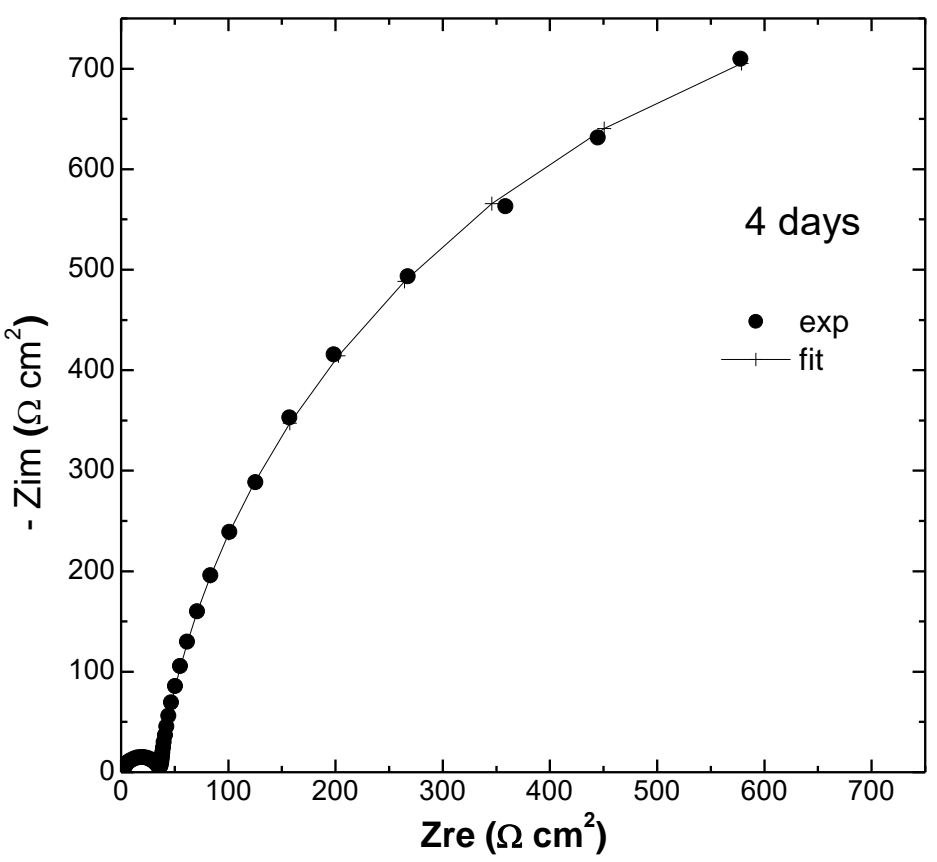

Figure 7 


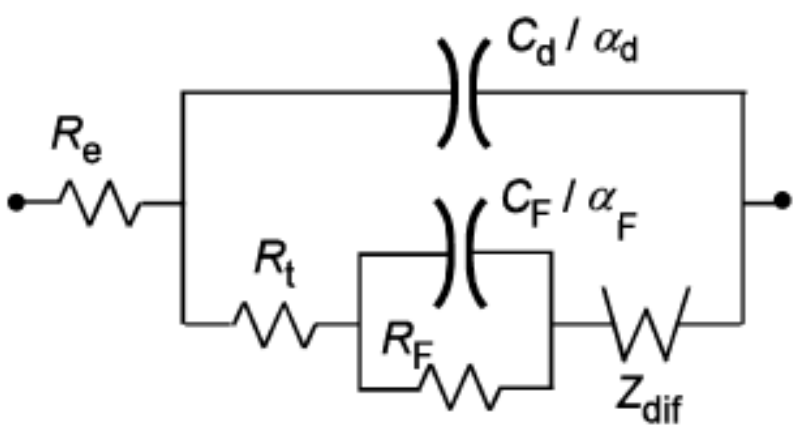

Figure 8 